Marquette University

e-Publications@Marquette

8-1999

\title{
Inhibition of the Aminopeptidase from Aeromonas proteolytica by Aliphatic Alcohols. Characterization of the Hydrophobic Substrate Recognition Site
}

\author{
Leila Ustynyuk \\ Utah State University \\ Brian Bennett \\ Marquette University, brian.bennett@marquette.edu \\ Tanya Edwards \\ Utah State University \\ Richard C. Holz \\ Marquette University, richard.holz@marquette.edu
}

Follow this and additional works at: https://epublications.marquette.edu/physics_fac

Part of the Physics Commons

\section{Recommended Citation}

Ustynyuk, Leila; Bennett, Brian; Edwards, Tanya; and Holz, Richard C., "Inhibition of the Aminopeptidase from Aeromonas proteolytica by Aliphatic Alcohols. Characterization of the Hydrophobic Substrate Recognition Site" (1999). Physics Faculty Research and Publications. 45.

https://epublications.marquette.edu/physics_fac/45 
Marquette University

e-Publications@Marquette

Physics Faculty Research and Publications/College of Arts and Sciences

This paper is NOT THE PUBLISHED VERSION; but the author's final, peer-reviewed manuscript. The published version may be accessed by following the link in the citation below.

Biochemistry, Vol. 38, No. 35 (1 August 1999): 11433-11439. DOI. This article is (C) American Chemical Society Publications and permission has been granted for this version to appear in $\underline{\mathrm{e}}-$ Publications@Marquette. American Chemical Society Publications does not grant permission for this article to be further copied/distributed or hosted elsewhere without the express permission from American Chemical Society Publications.

\section{Inhibition of the Aminopeptidase from Aeromonas proteolytica by Aliphatic Alcohols. Characterization of the Hydrophobic Substrate Recognition Site}

Leila Ustynyuk

Department of Chemistry and Biochemistry, Utah State University, Logan, Utah Brian Bennett

Department of Chemistry and Biochemistry, Utah State University, Logan, Utah Tanya Edwards

Department of Chemistry and Biochemistry, Utah State University, Logan, Utah Richard C. Holz

Department of Chemistry and Biochemistry, Utah State University, Logan, Utah 


\section{SUBJECTS:}

Alcohols, Peptides and proteins, Monomers, Hydrophobicity, Inhibitors

\section{Abstract}

Seven aliphatic and two aromatic alcohols were tested as reporters of the substrate selectivity of the aminopeptidase from Aeromonas proteolytica (AAP). This series of alcohols was chosen to systematically probe the effect of carbon chain length, steric bulk, and inhibitor shape on the inhibition of AAP. Initially, however, the question of whether AAP is denatured in the presence of aliphatic alcohols was addressed. On the basis of circular dichroism (CD), electronic absorption, and fluorescence spectra, the secondary structure of AAP, with and without added aliphatic alcohols, was unchanged. These data clearly indicate that AAP is not denatured in aliphatic alcohols, even up to concentrations of $20 \%(\mathrm{v} / \mathrm{v})$. All of the alcohols studied were competitive inhibitors of AAP with $K_{\mathrm{i}}$ values between 860 and $0.98 \mathrm{mM}$. The clear trend in the data was that as the carbon chain length increases from one to four, the $K_{\mathrm{i}}$ values increase. Branching of the carbon chains also increases the $K_{\mathrm{i}}$ values, but large bulky groups, such as that found in tert-butyl alcohol, do not inhibit AAP as well as leucine analogues, such as 3-methyl-1-butanol. The competitive nature of the inhibition indicates that the substrate and each alcohol studied are mutually exclusive due to binding at the same site on the enzyme. On the basis of EPR and electronic absorption data for Co(II)-substituted AAP, none of the alcohols studied binds to the dinuclear metallo-active site of AAP. Thus, reaction of the inhibitory alcohols with the catalytic metal ions cannot constitute the mechanism of inhibition. Combination of these data suggests that each of these inhibitors bind only to the hydrophobic pocket of AAP and, consequently, block the binding of substrate. Thus, the first step in peptide hydrolysis is the recognition of the $\mathrm{N}$-terminal amino acid side chain by the hydrophobic pocket adjacent to the dinuclear active site of AAP.

Aminopeptidases catalyze the hydrolysis of a wide range of $\mathrm{N}$-terminal amino acid residues from proteins and polypeptides (1-3). They are typically grouped into two distinct classes: those that are capable of removing a hydrophobic amino acid residue from the $\mathrm{N}$-terminus of a polypeptide chain and those that selectively remove a specific amino acid residue (1). The former group, for example, contains the bovine lens leucine aminopeptidase (bILAP) ${ }^{1}$ and the aminopeptidase from Aeromonas proteolytica (AAP), which are presumably involved in general degradation processes, while the latter group contains methionyl aminopeptidases (MetAP's) and proline aminopeptidases (AMPP's) which are more tightly regulated and have very specific physiological roles. Broadrange aminopeptidases, such as bILAP and AAP, are believed to play important roles in the metastatic process, particularly in the steps involving tumor cells traversing the basement membrane and collagenous stroma. This conclusion is based largely on the observation that several naturally occurring aminopeptidase inhibitors (i.e. bestatin, leuhistin, and actinonin) inhibit matrix degradation and invasion of extracellular matrixes by fibrosarcoma cells (4). On the other hand, MetAP's have recently been shown to be the target of the antiangiogenesis drugs ovalicin and fumagillin (5-9). Therefore, the inhibition of both broad-range and amino acid specific aminopeptidase activity in malignant tumors is critically important in preventing both tumor vasculature formation and the growth and proliferation of carcinoma cells.

Several dimetal aminopeptidases have been crystallographically characterized, and two general structural motifs have emerged: (i) All contain carboxylate-rich dinuclear metallo-active sites near the surface of the enzyme, and (ii) all possess at least one solvent accessible hydrophobic cavity adjacent to the dimetal active site. For AAP, this well-defined hydrophobic pocket is lined by two methionine, two phenylalanine, two tyrosine, two isoleucine, and two cysteine residues, which form a disulfide bond at the back of the pocket (10). A similar hydrophobic pocket was observed for the MetAP's from Escherichia coli, Pyrococcus furiosus, and humans $(9,11,12)$. For the 
MetAP from E. coli, the hydrophobic pocket provided the binding site for trimethyllead which was used as the heavy atom derivative in the X-ray structural determination (11). On the basis of these data, as well as several Xray crystal structures of inhibited forms of bILAP, AAP, and MetAP's, this pocket was suggested to function as the substrate recognition point in catalysis $(9,13-15$. Thus, characterization of the hydrophobic interactions between the enzyme and the substrate is critical if the observed substrate specificities of aminopeptidases are to be understood. The importance of understanding the substrate specificity and catalytic mechanisms of aminopeptidases is emphasized by the observation that the naturally occurring peptide analogue inhibitor, bestatin, was recently shown to significantly decrease HIV infection in males by inhibiting aminopeptidase activity (16).

To gain insight into the role of the hydrophobic pocket in catalysis, we have explored the binding of aliphatic alcohols to AAP. Analyses of both spectroscopic and kinetic data for the interaction of AAP with a series of aliphatic alcohols at $\mathrm{pH} \mathrm{8.0,} \mathrm{the} \mathrm{pH}$ maximum for catalytic activity, have provided information on the role of the hydrophobic pocket in catalysis. Comparison of the kinetic data obtained on the compounds tested as substrate mimics with known substrate trends has provided additional evidence for steric constraints within the active site of AAP that regulate peptide hydrolysis.

\section{Materials and Methods}

\section{Enzyme Purification.}

All chemicals used in this study were purchased commercially and were of the highest quality available. The aminopeptidase from Aeromonasproteolytica (AAP) was purified from a stock culture kindly provided by Professor Céline Schalk (17). Cultures were grown according to the previously published procedure (18) with minor modifications to the growth media (19). AAP was routinely purified, quantitated, and assayed as described in detail elsewhere (20).

\section{Spectrophotometric Assay of AAP.}

AAP activity was measured by the method of Prescott and Wilkes (18) as modified by Baker et al. (21). In this assay, the hydrolysis of $0.5 \mathrm{mM}$ I-leucine- $p$-nitroanilide ( $10 \mathrm{mM}$ Tricine, $\mathrm{pH} 8.0$ containing $0.1 \mathrm{mM} \mathrm{ZnSO}_{4}$ ) was measured spectrophotometrically at $25^{\circ} \mathrm{C}$ by monitoring the formation of $p$-nitroaniline. The extent of hydrolysis was calculated by monitoring the increase in absorbance at $405 \mathrm{~nm}\left(\Delta \varepsilon_{405}\right.$ value of $p$-nitroaniline of $10800 \mathrm{M}^{-1} \mathrm{~cm}^{-1}$ ) (22). One unit was defined as the amount of enzyme that releases $1 \mu$ mole of $p$-nitroaniline at $25^{\circ} \mathrm{C}$ in $60 \mathrm{~s}$. The specific activity of purified AAP was typically found to be 120 units/mg of enzyme. This value is identical to that reported by Prescott and Wilkes (18). All spectrophotometric assays were performed on a Shimadzu UV-3101PC spectrophotometer equipped with a constant temperature holder and a Haake (Type 423) constant-temperature circulating bath. Enzyme concentrations were determined from the absorbance at 278 $\mathrm{nm}$ with the value $\varepsilon_{278}=41800 \mathrm{M}^{-1} \mathrm{~cm}^{-1}(23)$.

\section{Kinetic Studies.}

The kinetic parameters $v$ (velocity), $k_{\text {cat }}\left(V_{\max } /[\mathrm{E}]_{0}\right), K_{\mathrm{m}}$ (Michaelis constant), and $K_{\mathrm{i}}$ (inhibition constant) were determined at $\mathrm{pH} 8.0$ spectrophotometrically by recording the initial velocity of the hydrolysis of I-leucine-pnitroanilide at $25^{\circ} \mathrm{C}$ in triplicate. Aliphatic alcohol concentrations ranged from 0 to $0.2 \mathrm{M}$ depending on the alcohol used but from 0 to $2 \mathrm{M}$ for methanol which was the weakest inhibitor of AAP tested. The linearity of the progress curves for product formation both in the absence and presence of inhibitor indicated that each alcohol studied was in rapid equilibrium with AAP. Depletion of enzyme-bound zinc was prevented by the addition of 0.1 $\mathrm{mM} \mathrm{ZnSO}_{4}$ to all buffers. 
Co(II)-Substituted AAP Samples.

Mono- and dicobalt-substituted forms of the enzyme ([Co_(AAP)] and [CoCo(AAP)]) were prepared and assayed as in earlier work (20). Briefly, AAP was dialyzed for $72 \mathrm{~h}$ at $4{ }^{\circ} \mathrm{C}$ against $10 \mathrm{mM}$ 1,10-phenanthroline monohydrochloride in $50 \mathrm{mM}$ Hepes buffer, $\mathrm{pH} 7.5$, and then exhaustively dialyzed against chelex-treated Hepes buffer. Metal insertion was effected by direct addition, with efficient mixing, of 1 equiv of $\mathrm{MCl}_{2}$ (where $\mathrm{M}=\mathrm{Co}$ or $\mathrm{Zn} ; \geq 99.999 \% \mathrm{CoCl}_{2}$, Strem Chemicals, Newburyport, $\mathrm{MA} ; 99.999 \% \mathrm{ZnCl}_{2}$, Aldrich) followed by a $30 \mathrm{~min}$ incubation period at $20-25^{\circ} \mathrm{C}$. The second metal was then inserted in the same manner.

\section{Spectroscopic Measurements.}

Fluorescence spectra were measured on a Gilford Fluoro IV spectrofluorometer. Spectra were recorded on $1 \mu \mathrm{M}$ AAP samples in $2 \mathrm{~mL}$ fluorescence cuvettes with a $1 \mathrm{~cm}$ path length. Titrations were run by exciting at $280 \mathrm{~nm}$ and adding small amounts of the desired alcohol. All spectra were baseline subtracted against buffer and dilution corrected. Circular dichroism (CD) spectra were recorded on an Aviv 62A DS circular dichroism spectrometer. Spectra were fit using IgorPro with three structural forms of a poly(I-lysine) peptide (24). Lowtemperature EPR spectroscopy was performed on Co(II)-substituted AAP using a Bruker ESP-300E spectrometer equipped with an ER 4116 DM dual mode X-band cavity and an Oxford Instruments ESR-900 helium flow cryostat as described previously (20). Spectra were recorded at a modulation frequency of $100 \mathrm{kHz}$, a modulation amplitude of $1.26 \mathrm{mT}(12.6 \mathrm{G})$, a sweep rate of $10 \mathrm{mT} \mathrm{s}^{-1}$, and microwave frequencies of approximately $9.65 \mathrm{GHz}$ : precise microwave frequencies were recorded for individual spectra to ensure precise $g$ alignment. Other EPR running parameters are specified in the figure legends for individual samples. Enzyme concentrations for EPR studies were typically 1-2 mM.

\section{Results}

\section{Effect of Alcohols on the Secondary Structure of AAP.}

Organic solvents have previously been shown to cause proteins to undergo conformational changes that can result in aggregation $(25,26)$. Aggregation of AAP is, however, observed at high protein concentrations in the absence of alcohols or detergents. Purified samples of AAP (>1 mM) stored for up to 2 weeks at $4{ }^{\circ} \mathrm{C}$ in Hepes buffer, pH 7.5, containing 20\% (v/v) 2-propanol (iso-PrOH), showed no observable aggregation. Moreover, no loss in enzymatic activity is observed once the alcohol or detergent is removed. To determine if AAP is denatured upon the addition of aliphatic alcohols, we recorded circular dichroism (CD) spectra of AAP in the absence and presence of a series of aliphatic alcohols (Figure 1). Initially, we recorded the CD spectrum of AAP at pH 8.0 in $10 \mathrm{mM}$ Tricine buffer without added alcohol (Figure 2). On the basis of the X-ray crystal structure of AAP, its secondary structure consists of $35.4 \% \alpha$-helix, 3.8\% 3,10-helix, $17.2 \% \beta$-sheet, and $43.6 \%$ random coil. Using CD spectra of crystallographically characterized peptides with the appropriate secondary structures (Figure 2, inset), the CD spectrum of AAP was fit to the structurally determined secondary structure types (Figure 2B). As seen in Figure 2, the resulting fit was poor. The best fit obtained for the CD spectrum of AAP resulted from the inclusion of $50 \% \alpha$-helix, $20 \% \beta$-sheet, and $30 \%$ random coil (Figure $2 \mathrm{C}$ ). Contributions to the CD spectrum of AAP that are unaccounted for by the model systems may arise from 3,10-helical structure or as a result of the disulfide bond. Furthermore, the presence of exposed hydrophobic patches may well lead to a slightly altered secondary structure in the crystal where the protein may adopt a conformation that maximizes intermolecular hydrophobic interactions. 
<smiles>[R]C(=O)C([R])NC(=O)C(N)CC(C)C</smiles>

Leu-peptide (Substrate)<smiles>CCCO</smiles><smiles>CCO</smiles>

Methanol Ethanol<smiles>CC(O)O</smiles>

n-Propanol<smiles>CCCCO</smiles>

tert-Butanol $\quad n$-Butanol 3-Methyl-1-Butanol<smiles>OCc1ccccc1</smiles>

\section{Phenol Benzyl Alcohol}

Figure 1 Drawings of the leucine-substrate of AAP along with the seven aliphatic and two aromatic alcohols studied.

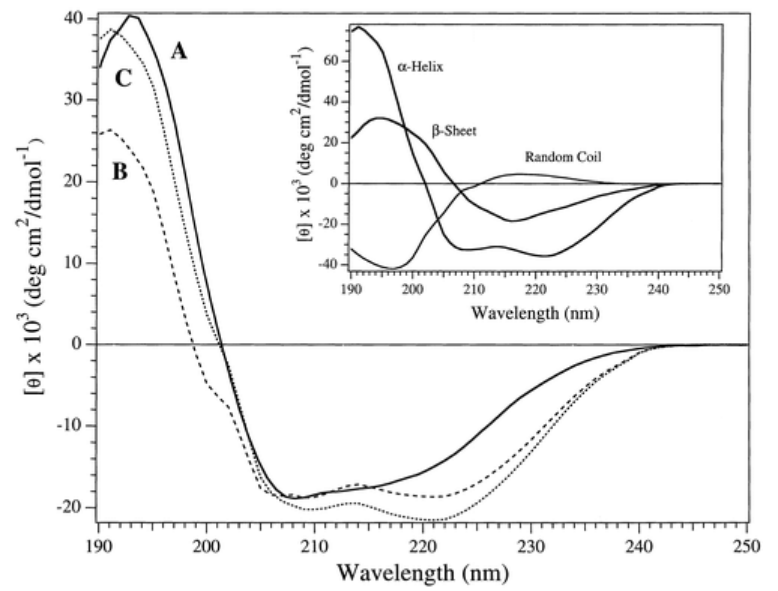

Figure $2 \mathrm{CD}$ spectrum of a $0.2 \mathrm{mg} / \mathrm{mL}$ sample of AAP at $\mathrm{pH} 8.0$ in $10 \mathrm{mM}$ Tricine buffer containing $0.1 \mathrm{mM}$ $\mathrm{ZnSO}_{4}$ 9A) without added alcohol (solid line). (B) Fit of the CD spectrum of AAP using the crystallographically determined percentages of $\alpha$-helix, $\beta$-sheet, and random coil of $39 \%, 17 \%$, and $44 \%$, respectively (dashed line). Fit of the CD spectrum of AAP using $50 \% \alpha$-helix, $20 \% \beta$-sheet, and $30 \%$ random coil (dotted line). Inset: Representative CD spectra of peptides with $\alpha$-helix, $\beta$-sheet, and random coil structures.

CD spectra of $6.9 \mu \mathrm{M}$ solutions of AAP in the presence of each aliphatic alcohol studied $(5 \%(\mathrm{v} / \mathrm{v}))$ are shown in Figure 3. Spectra were also obtained for AAP at iso-PrOH concentrations ranging from 5 to 20\% (v/v) (Figure 3, inset). Each AAP-alcohol sample studied, even up to $20 \%$ alcohol (v/v), showed a small positive increase in ellipticity at $196 \mathrm{~nm}$ and a small negative increase in ellipticity between 210 and $230 \mathrm{~nm}$. If AAP were being denatured by any of the alcohols studied, a CD spectrum reminiscent to that of the random coil spectrum would be expected (Figure 2, inset). These data clearly indicate that AAP is not denatured in aliphatic alcohols, even up to concentrations of $20 \%(\mathrm{v} / \mathrm{v})$. 


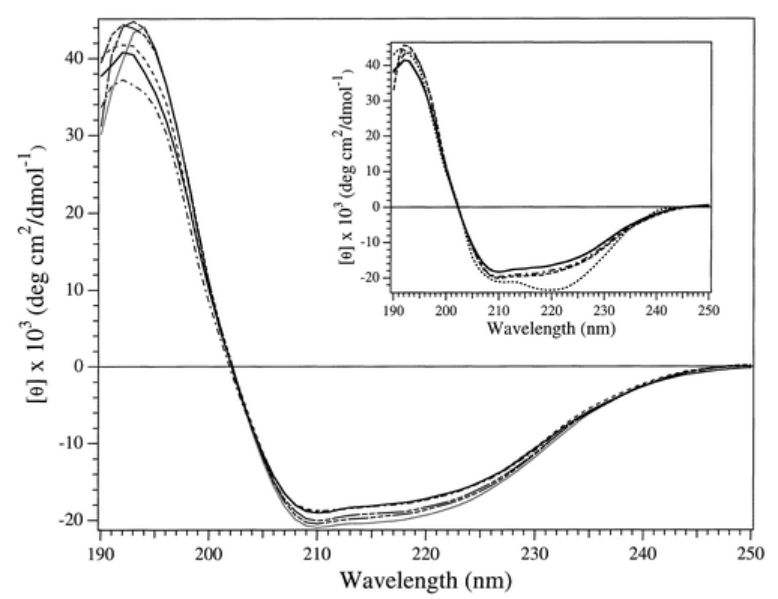

Figure $3 \mathrm{CD}$ spectra of $0.2 \mathrm{mg} / \mathrm{mL}$ samples of AAP at pH 8.0 in $10 \mathrm{mM}$ Tricine buffer containing $0.1 \mathrm{mM}$ $\mathrm{ZnSO}_{4}$ without added alcohol (solid line), $5 \% \mathrm{MeOH}(\mathrm{v} / \mathrm{v})$ (triple-dashed line), $5 \% \mathrm{EtOH}(\mathrm{v} / \mathrm{v}$ ) (dashed line), $5 \%$ iso-PrOH (v/v) (dotted line), $5 \% n-\mathrm{BuOH}(\mathrm{v} / \mathrm{v})$ (dot-dashed line), $5 \%$ tert-BuOH (v/v) (double-dashed line). Inset: $\mathrm{CD}$ spectra of $0.2 \mathrm{mg} / \mathrm{mL}$ samples of AAP at pH 8.0 in $10 \mathrm{mM}$ Tricine buffer containing $0.1 \mathrm{mM} \mathrm{ZnSO}_{4}$ without added alcohol (solid line), $5 \%$ iso-PrOH (dot-dashed line), and $20 \%$ iso-PrOH (dashed line). Fit of the CD spectrum of AAP $+20 \%$ iso-PrOH (v/v) using $55 \% \alpha$-helix, $30 \% \beta$-sheet, and $15 \%$ random coil (dotted line).

Electronic absorption and fluorescence spectra also provide characteristic features that can be used as a fingerprint of the native secondary structure of an enzyme. To further establish that AAP is not denatured upon the addition of aliphatic alcohols, we recorded electronic absorption spectra of AAP at pH 8.0 in $10 \mathrm{mM}$ Tricine buffer both in the absence and presence of each of the alcohols studied. Typical of all proteins, in the far-UV region (190-240 nm) the absorbing group is principally peptide bonds. There is a weak but broad $\mathrm{n} \rightarrow \pi^{*}$ transition centered around $210 \mathrm{~nm}$ and an intense $\pi \rightarrow \pi^{*}$ transition about $190 \mathrm{~nm}$ (data not shown). Aromatic amino acid side chains (especially tryptophan) and disulfide bonds also contribute to the far-UV spectrum. In the near-UV, aromatic amino acid side chains (phenylalanine, tyrosine, and tryptophan) exhibit an intense $\pi \rightarrow \pi^{*}$ transition in the 250-290 nm range (27). For AAP, no changes in absorption spectra of enzyme solutions without aliphatic alcohols compared to samples with 5-20\% (v/v) of alcohols were observed. Fluorescence spectra recorded for AAP in the presence of each aliphatic alcohol studied at 1-5\% $(\mathrm{v} / \mathrm{v})$ concentrations showed an increase in the fluorescence intensity as aliphatic alcohol was added. In addition, fluorescence spectra were also obtained for AAP + iso- $\mathrm{PrOH}$ solutions at $\mathrm{pH} 8.0$ in $10 \mathrm{mM}$ Tricine buffer in the presence of 0-50\% (v/v) alcohol in the 300-450 $\mathrm{nm}$ range (Figure 4). For iso- $\mathrm{PrOH}$, titration of alcohol up to a $50 \%$ (v/v) solution showed a linear increase in fluorescence intensity (Figure 4, inset). These data suggest that the protein in aqueous solution (i.e. minus alcohol) exhibits fluorescence quenching as a result of solvent access to fluorophores. The combination of electronic absorption and fluorescence data with $C D$ data further substantiates that AAP is not denatured in the presence of alcohols. 


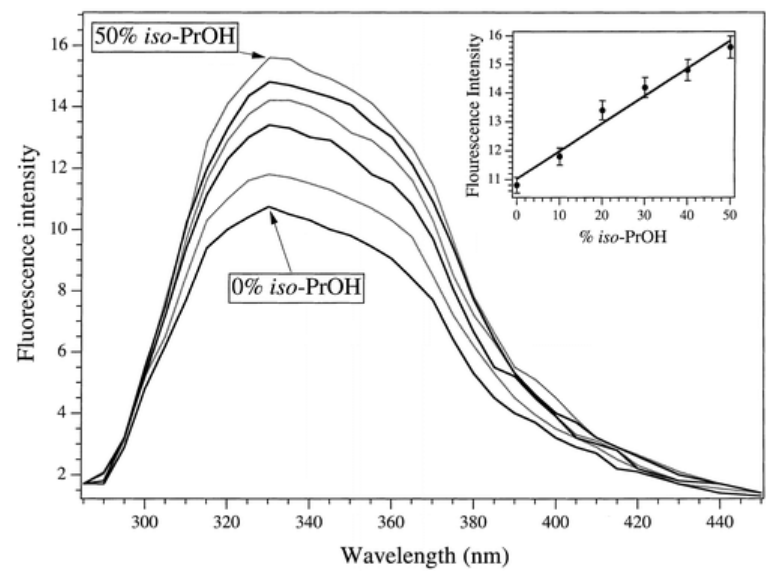

Figure 4 Fluorescence spectral titration of a $1 \mu \mathrm{M}$ AAP sample at $\mathrm{pH} 8.0$ in $10 \mathrm{mM}$ Tricine buffer containing 0.1 $\mathrm{mM} \mathrm{ZnSO}_{4}$ with 0-50\% iso-PrOH. Inset: Plot of fluorescence intensity vs \% of iso-PrOH added.

\section{Inhibition of AAP by Aliphatic Alcohols at pH 8.0.}

AAP samples stored in $10 \mathrm{mM}$ Tricine buffer, $\mathrm{pH} 8.0$, and $0.1 \mathrm{mM} \mathrm{ZnSO}_{4}$ solution for 10 days at room temperature showed no decrease in catalytic activity but, in the presence of up to $20 \%(\mathrm{v} / \mathrm{v})$ of iso-PrOH, AAP showed no catalytic activity. Upon washing the AAP + iso-PrOH sample with $10 \mathrm{mM}$ Tricine buffer, pH 8.0, and $0.1 \mathrm{mM} \mathrm{ZnSO}_{4}$ to remove all of the iso-PrOH, compete recovery of the enzymatic activity was observed. Similar experiments were performed on each of the aliphatic alcohols studied, and in each case, the loss of catalytic activity was completely reversible. Therefore, the inhibition of AAP by all eight of the aliphatic alcohols studied showed no irreversible damage to AAP.

To elucidate the role of the hydrophobic pocket adjacent to the dinuclear $\mathrm{Zn}$ (II) active site of AAP, the inhibition of a series of aliphatic alcohols as well as two aromatic alcohols (Figure 1) toward the hydrolysis of I-leucine-pnitroanilide by AAP was investigated. The initial rates of hydrolysis of I-leucine- $p$-nitroanilide were monitored as a function of alcohol concentration in $10 \mathrm{mM}$ Tricine buffer, $\mathrm{pH}$ 8.0, containing $0.1 \mathrm{mM} \mathrm{ZnSO}_{4}$. Triplicate activity assay determinations at four concentrations of alcohol (0-0.2 or 0-2.0 M) were made for each of 8 substrate concentrations $(6-60 \mu \mathrm{M})$. A representative double-reciprocal plot of velocity $(v)$ vs substrate concentration ([S]) for iso-PrOH is shown in Figure 5. The double-reciprocal plot of velocity vs [iso-PrOH] shows a pattern characteristic of competitive inhibition. The experimental data were fit to the Michaelis-Menten equation for competitive inhibition reported by Cleland (28). Under these conditions, the Michaelis constant $\left(K_{\mathrm{m}}\right)$ for Ileucine- $p$-nitroanilide was found to be $13 \pm 3 \mu \mathrm{M}$ in excellent agreement with that previously reported by Chen et al. (19) and Prescott et al. (18). The inhibition constant, $K_{\mathrm{i}}$, for the binding of iso-PrOH to AAP was found to be $8.0 \pm 2.0 \mathrm{mM}$. For pure competitive inhibition, a linear relationship is expected for plots of $K_{\operatorname{mapp}} / V_{\max }$ vs [I] (Figure 5, inset) (29). A linear relationship is indeed observed, indicating that iso-PrOH is a pure competitive inhibitor of the hydrolysis of I-leucine- $p$-nitroanilide by AAP. 


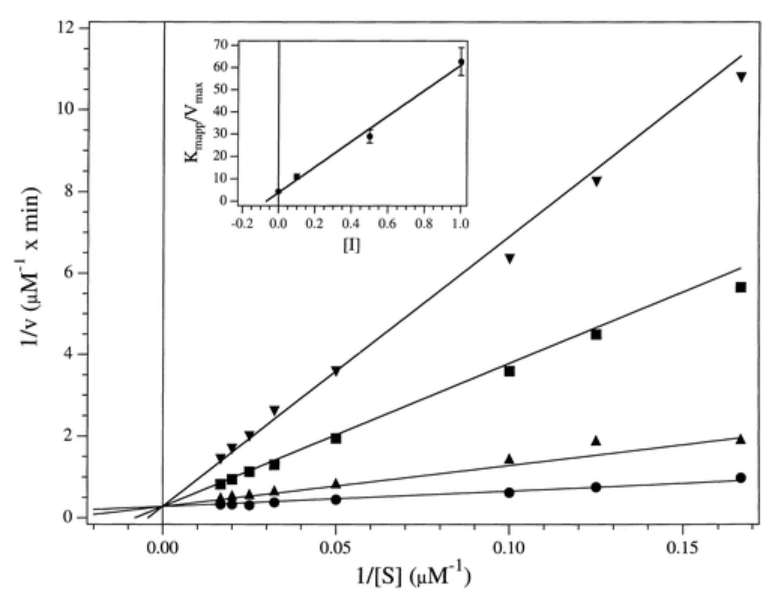

Figure 5 Double-reciprocal plot of 1 /velocity vs 1 /substrate concentration at various iso-PrOH concentrations. The lines result from a fit of the entire data set to the Michaelis-Menten equation for competitive inhibition. The solutions were buffered with $10 \mathrm{mM}$ Tricine, $\mathrm{pH}$ 8.0. iso-PrOH concentrations (v/v) were $0.0 \%(\cdot), 0.1 \%(\Delta)$, $0.5 \%(-)$, and $1.0 \%(\nabla)$. Inset: Replot of the data from Figure $5, K_{\operatorname{mapp}} / V_{\max }$ vs. [I].

Seven aliphatic and two aromatic alcohols were tested as reporters of the substrate selectivity of AAP. This series of alcohols was chosen to systematically probe the effects of carbon chain length, steric bulk, and inhibitor shape on the inhibition of AAP (Figure 1). All of the alcohols studied are competitive inhibitors of AAP with $K_{\mathrm{i}}$ values between 860 and $0.98 \mathrm{mM}$ (Table 1$)$. Not surprisingly, methanol $\left(K_{\mathrm{i}}=860 \mathrm{mM}\right)$ is the weakest inhibitor of AAP followed by ethanol $\left(K_{\mathrm{i}}=80 \mathrm{mM}\right)$ and $n$-propanol $\left(K_{\mathrm{i}}=11 \mathrm{mM}\right)$. tert-Butyl alcohol $\left(K_{\mathrm{i}}=10 \mathrm{mM}\right)$ and 2-propanol $\left(K_{\mathrm{i}}=8 \mathrm{mM}\right)$ are similar in their ability to inhibit AAP while $n$-butanol $\left(K_{\mathrm{i}}=2.7 \mathrm{mM}\right)$, phenol $\left(K_{\mathrm{i}}=\right.$ $4.0 \mathrm{mM})$, and benzyl alcohol $\left(K_{\mathrm{i}}=2.6 \mathrm{mM}\right)$ are stronger inhibitors by comparison. The best inhibitor studied was 3-methyl-1-butanol $\left(K_{\mathrm{i}}=0.98 \mathrm{mM}\right)$, which closely mimics the structure of leucine (Figure 1$)$. Aromatic alcohols are also strong inhibitors of AAP by comparison to the other alcohols studied with benzyl alcohol being the better of the two aromatic alcohols studied. This is consistent with the previously reported activity trend for AAP in that $\mathrm{N}$-terminal phenylalanine groups are second, only to leucine, as preferred substrates for AAP (18).

Table 1: Summary of the Inhibition Constants for Aliphatic Alcohol Inhibition of AAP at pH 8.0

\begin{tabular}{|l|l|}
\hline inhibitor & $K_{\mathrm{i}}(\mathrm{mM})$ \\
\hline methanol & $860 \pm 20$ \\
\hline ethanol & $80 \pm 8$ \\
\hline$n$-propanol & $11 \pm 2$ \\
\hline tert-butanol & $10 \pm 2$ \\
\hline 2-propanol & $8 \pm 2$ \\
\hline$n$-butanol & $2.7 \pm 0.3$ \\
\hline phenol & $4.0 \pm 0.4$ \\
\hline benzyl alcohol & $2.6 \pm 0.3$ \\
\hline 3-methyl-1-butanol & $0.98 \pm 0.1$ \\
\hline
\end{tabular}

EPR and Electronic Absorption Studies of [Co_(AAP)] and [CoCo(AAP)] in the Presence of Aliphatic Alcohols.

Upon the addition of 1 equiv of Co(II) to apo-AAP ([Co_(AAP)]) in the absence of alcohol, a distinctive EPR signal was observed in which the ${ }^{59} \mathrm{Co}$ hyperfine pattern was not centered on the low-field absorption (Figure 6A). As previously reported (20), this signal could not be simulated as a single species but subtraction of EPR spectra 
recorded at different temperatures revealed that two species were present. Upon the addition of $20 \%(\mathrm{v} / \mathrm{v})$ isoPrOH to [Co_(AAP)] (Figure 6B) no change in the EPR spectrum was observed. Similarly, the EPR spectrum of [CoCo(AAP)] (Figure 6C) was recorded in the absence of alcohol and, as previously reported (20), was simulated as a single axial species. Upon the addition of up to $20 \%$ iso- $\mathrm{PrOH}$ at $\mathrm{pH} 8.0$, no change in the EPR spectrum was observed (Figure 6D). In a comparable set of experiments, electronic absorption spectra of [Co_(AAP)] and [CoCo(AAP)] in the absence and presence of $20 \%$ iso- $\mathrm{PrOH}(\mathrm{v} / \mathrm{v})$ were recorded $(20,30,31)$. Again, no changes in the electronic absorption spectra were detected. These data indicate that the coordination spheres of the metal ions in the active site remain unchanged upon the addition of even relatively high concentrations of iso-PrOH. Thus the detailed structure of the site of catalysis is unaffected by iso-PrOH. As well as confirming the integrity of the active site structure of the enzyme in dilute alcoholic solution, these data also preclude the direct interaction of the inhibitor molecule with the catalytic metal ions. Thus. reaction of the inhibitory alcohols with the catalytic metal ions cannot constitute the mechanism of inhibition.

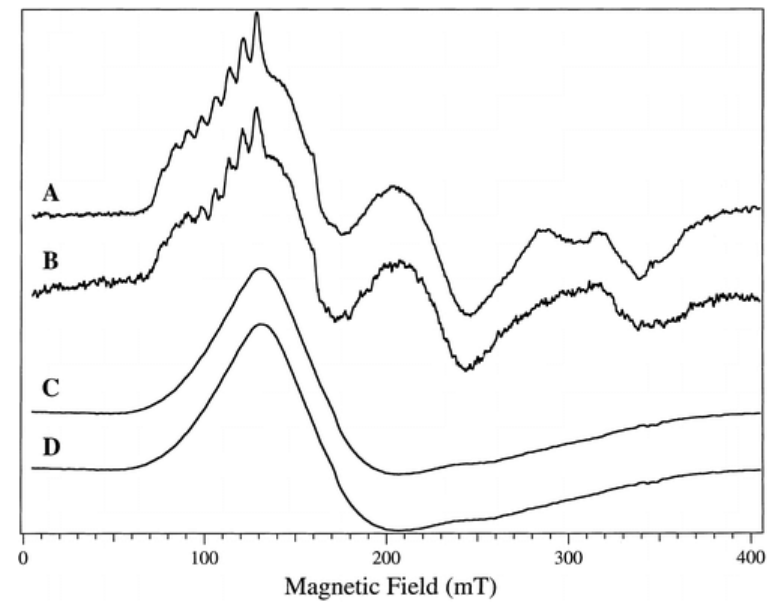

Figure 6 (A) EPR spectrum of [Co_(AAP)] recorded at $10 \mathrm{~K}, 0.2 \mathrm{~mW}$ microwave power, in the presence of $20 \%$ iso-PrOH (v/v). (B) EPR spectrum of [Co_(AAP)] recorded at $10 \mathrm{~K}, 0.2 \mathrm{~mW}$ microwave power, without added isoPrOH. (C) EPR spectrum of [CoCo(AAP)] at $10 \mathrm{~K}, 0.2 \mathrm{~mW}$ microwave power, in the presence of $20 \%$ iso-PrOH (v/v). (D) EPR spectrum of [CoCo(AAP)] at $10 \mathrm{~K}, 0.2 \mathrm{~mW}$ microwave power, without added iso-PrOH.

\section{Discussion}

The aminopeptidase from Aeromonas proteolytica (AAP) has been shown to require peptide substrates with a free $\alpha$-amino group in the l-configuration. AAP will hydrolyze di- and tripeptides as well as amino acid amides, esters, $\beta$-naphthylamides, and $p$-nitroanalides (18). AAP, like the aminopeptidases from bovine lens (blLAP) and Streptomyces griseus (SAP), prefers hydrophobic residues in the $\mathrm{NH}_{2}$-terminal position (32-36). On the basis of X-ray crystallographic studies performed on each of these enzymes, a well-defined hydrophobic pocket resides adjacent to the dinuclear Zn(II) active sites (10, 34, 37). For AAP, this site is made up of Met180, Ile193, Cys223, Tyr225, Cys227, Met242, Phe248, Tyr251, and Ile255. The two Cys residues form a disulfide bond at the back of this pocket, and on the basis of X-ray crystallographic data, this pocket was suggested to act as the substrate recognition point on the enzyme $(10,15)$. To gain insight into the role of this hydrophobic pocket in catalysis, we have studied the inhibition of AAP by a series of aliphatic alcohols. Aliphatic alcohols were chosen for this study on the basis of the observation that precipitation and eventual gelatinization of AAP was observed at high enzyme concentrations ( $>1 \mathrm{mM}$ ). This gelatinization process was effectively prevented by the addition of $20 \%(\mathrm{v} / \mathrm{v})$ of iso-PrOH. It was hypothesized that the formation of gelatinous material was the result of enzyme-enzyme interactions at high protein concentrations via the exposed hydrophobic patch identifiable in the crystal structure. This hydrophobic patch is adjacent to the catalytic site and is therefore a likely candidate 
for recognition and binding of hydrophobic substrates for the enzyme. That iso-PrOH prevented protein aggregation by perhaps binding to this region suggested that information about the nature of substrate binding may be forthcoming from a study of the effects of iso- $\mathrm{PrOH}$ and related compounds on the properties of the enzyme.

Initially, the question of whether AAP is denatured in the presence of aliphatic alcohols was addressed. Activity measurements taken for AAP in a $20 \%$ iso- $\mathrm{PrOH}(\mathrm{v} / \mathrm{v})$ buffered solution revealed that AAP is inactive under these conditions. However, upon washing with buffer containing no iso-PrOH, full enzymatic activity was regained suggesting that no irreversible denaturation occurs. To better address the nature of the secondary structure of AAP in aliphatic alcohol solution, CD spectra were recorded both in the absence and presence of various concentrations of iso-PrOH. As shown in Figures 2 and 3, the secondary structure of AAP is unchanged in the presence of $5 \%(\mathrm{v} / \mathrm{v})$ solutions of aliphatic alcohol and, even up to $20 \%(\mathrm{v} / \mathrm{v})$ solutions of iso-PrOH, the secondary structure of AAP remains unperturbed. In fact, in $20 \%$ iso-PrOH (v/v) solutions, slight increases in $\alpha-$ helix and $\beta$-sheet content is observed, on the basis of spectral simulations, with small decreases in the amount of random coil. In an elegant study by Kilbanov and co-workers, the decrease in activity of the serine protease Subtillian (Carlsburg) was studied in anhydrous actetonitrile (38). One of the conclusions derived from these studies was that the exclusion of water diminished the conformational flexibility of the enzyme. On the basis of CD data for AAP and the fits of these data to the amount of secondary structural features present, our results are consistent with a loss of enzyme flexibility at high alcohol concentrations in that the amount of random coil decreases. These data suggest that the secondary structure of AAP remains largely intact upon the addition of aliphatic alcohols.

The observation that AAP is not denatured in alcohol solutions is substantiated by electronic absorption and fluorescence spectroscopic measurements. At concentrations of iso-PrOH even up to $50 \%(\mathrm{v} / \mathrm{v})$ an increase in fluorescence intensity is observed and a plot of fluorescence intensity vs \% iso-PrOH is linear. The observed fluorescence spectra reflect protein chromophores, which, in this case, are primarily tryptophan. AAP has five tryptophan residues, three of which are near the surface of the enzyme while two are buried (10). None of the five tryptophan residues are near the dimetal active site or the hydrophobic pocket nor are they near each other. Since the sensitivity of tryptophan fluorescence is related to the collisional quenching of solvent molecules, the increase in fluorescence intensity of AAP in the presence of aliphatic alcohols is the result of shielding the tryptophan residues from the solvent water molecules. These data are also consistent with CD and absorption data, which indicate that AAP is not denatured in the presence of aliphatic alcohols. The observation that AAP is not denatured in aqueous-organic mixtures is not unprecedented. Several enzymes, such as lysozyme, have been shown to be nearly fully catalytically active even in neat organic solvents (39). Similarly, Vimelysin, a metalloproteinase, has been shown to retain activity for $48 \mathrm{~h}$ at ethanol concentrations up to $50 \%$ $(\mathrm{v} / \mathrm{v})(40)$.

An interesting finding in this study is the fact that each aliphatic and aromatic alcohol studied is a weak competitive inhibitor of AAP. Given the fact that AAP is not denatured upon the addition of alcohols, the competitive nature of the inhibition indicates that the substrate, and each alcohol studied, are mutually exclusive due to binding at the same site on the enzyme. Prescott and Wilkes showed that AAP has the strongest preference for substrates with an N-terminal leucine group (18). The clear trend in the kinetic data is that as the carbon chain length increases from one to four, the $K_{\mathrm{i}}$ value decreases. Branching of the carbon chains also decreases the $K_{\mathrm{i}}$ value, but large bulky groups, such as that found in tert-butyl alcohol, do not inhibit AAP as well as leucine analogues, such as 3-methyl-1-butanol. On the basis of the EPR and electronic absorption data of Co(II)-substituted AAP, none of the alcohols studied binds to the dinuclear metallo-active site of AAP. Combination of these data suggests that each of these inhibitors bind only to the hydrophobic pocket of AAP and, consequently, blocks the binding of substrate. Since it is well established that divalent metal ions are 
required for enzymatic activity (41), and several transition state and substrate analogue inhibitors have been shown to bind directly to the active site metal ions $(20,30,31,42)$, the initial catalytic step in the hydrolysis of peptides by AAP must be substrate binding to the hydrophobic pocket adjacent to the metallo-active site. Comparison of the $K_{\mathrm{i}}$ values obtained for the series of alcohols studied with other known inhibitors of AAP also suggests that none of the alcohol inhibitors studied bind to the dinuclear active site. For example, Ileucinephosphonic acid (LPA), a transition state analogue inhibitor, competitively inhibits AAP with a $K_{\mathrm{i}}$ of $7 \mu \mathrm{M}$ (42). LPA has been shown by spectroscopic methods to bind both metal ions of the dinuclear active site of AAP (42). On the other hand, $N$-valeramide, a substrate analogue inhibitor of AAP, was reported to be a weak competitive inhibitor $\left(K_{\mathrm{i}}=5.2 \mathrm{mM}\right)$ and does not bind to the dinuclear active site of AAP (43). The combination of these data with the $K_{\mathrm{i}}$ values for the alcohols studied herein suggests that a significant amount of the overall binding interaction for substrate is provided by the hydrophobic pocket, adjacent to the dinclear active site.

Inclusion of the data presented herein into the previously reported mechanism of action for AAP $(19,20)$ indicates that the initial recognition point of peptide hydrolysis is the hydrophobic pocket adjacent to the dinuclear active site of AAP. The substrate selectivity of AAP is also highly dependent on the size and shape of the N-terminal amino acid side chain. The only X-ray crystallographic data available for AAP bound by an inhibitor are of the transition state analogue inhibitor d-iodophenylalanine hydroxamate. In this structure, the phenyl ring of the inhibitor is stacked on the ring of Phe244 while that ring of Phe248 is displaced to accommodate the inhibitor (15). The displacement of Phe248 may account for the increased $K_{\mathrm{i}}$ value for benzyl alcohol vs 3-methyl-1-butanol, which may not require Phe248 to be displaced upon binding. Clearly, additional structural information is required to fully characterize the selectivity of the hydrophobic pocket in AAP. That the hydrophobic pocket is critical in substrate recognition of aminopeptidases is underscored by a recent study on the yeast methionyl aminopeptidase (44). In this elegant study, several site-directed mutants of hydrophobic pocket residues were constructed which revealed alterations in catalytic activity and substrate specificity. Since abnormal aminopeptidase activity has been associated with many health conditions and pathologies including HIV and several cancers $(2-7,9,16)$, a detailed understanding of the substrate recognition properties of aminopeptidases will ultimately assist in the design and synthesis of new antiviral and/or anticancer chemotherapeutic agents that specifically target these enzymes.

\section{Acknowledgment}

The authors would like to thank Professor Ann Aust for the use of the spectrofluorometer and Professor Sheila David for the use of the circular dichroism spectrometer.

This work was supported by the National Science Foundation (Grant CHE-9816487; R.C.H.).

\section{References}

1 Taylor, A. (1996) in Molecular Biology Intelligence Unit (Co, R. G. L., Ed.) pp 1-219, R. G. Landes Co., Austin, TX.

2 Taylor, A. (1993) FASEB J.7, 290-298.

3 Taylor, A. (1993) Trends Biochem. Sci.18, 167-172.

4 Fujii, H., Nakajima, M., Aoyagi, T., and Tsuruo, T. (1996) Biol. Pharm. Bull.19, 6-10.

5 Taunton, J. (1997) Chem. Biochem.4, 493-496.

6 Griffith, E. C., Su, Z., Turk, B. E., Chen, S., Chang, Y.-H., Wu, Z., Biemann, K., and Liu, J. O. (1997) Chem. Biol.4, 461-471.

7 Sin, N., Meng, L., Wang, M. Q., Wen, J. J., Bornmann, W. G., and Crews, C. M. (1997) Proc. Natl. Acad. Sci. U.S.A.94, 6099-6103.

8 Lowther, W. T., McMillen, D. A., Orville, A. M., and Matthews, B. W. (1998) Proc. Natl. Acad. Sci. U.S.A.95, 12153-12157.

9 Liu, S., Windom, J., Kemp, C. W., Crews, C. M., and Clardy, J. (1998) Science282, 324-327. 
10 Chevrier, B., Schalk, C., D'Orchymont, H., Rondeau, J.-M., Moras, D., and Tarnus, C. (1994) Structure2, 283-291.

11 Roderick, S. L., and Matthews, B. W. (1993) Biochemistry32, 3907-3912.

12 Tahirov, T. H., Oki, H., Tsukihara, T., Ogasahara, K., Yutani, K., Ogata, K., Izu, Y., Tsunasawa, S., and Kato, I. (1998) J. Mol. Biol.284, 101-124.

13 Sträter, N., Lipscomb, W. N., Klabunde, T., and Krebs, B. (1996) Angew. Chem., Int. Ed. Engl.35, 2024-2055.

14 Sträter, N., and Lipscomb, W. N. (1995) Biochemisty34, 9200-9210.

15 Chevrier, B., D'Orchymont, H., Schalk, C., Tarnus, C., and Moras, D. (1996) Eur. J. Biochem.237, 393-398.

16 Pulido-Cejudo, G., Conway, B., Proulx, P., Brown, R., and Izaguirre, C. A. (1997) Antivir. Res.36, 167-177.

17 Schalk, C., Remy, J.-M., Chevrier, B., Moras, D., and Tarnus, C. (1992) Arch. Biochem. Biophys.294, 91-97.

18 Prescott, J. M., and Wilkes, S. H. (1976) Methods Enzymol.45B, 530-543.

19 Chen, G., Edwards, T., D'souza, V. M., and Holz, R. C. (1997) Biochemistry36, 4278-4286.

20 Bennett, B., and Holz, R. C. (1997) J. Am. Chem. Soc.119, 1923-1933.

21 Baker, J. O., Wilkes, S. H., Bayliss, M. E., and Prescott, J. M. (1983) Biochemistry22, 2098-2103.

22 Tuppy, H., Wiesbauer, W., and Wintersberger, E. (1962) Hoppe-Seyler's Z Physiol. Chem.329, 278-288.

23 Prescott, J. M., Wilkes, S. H., Wagner, F. W., and Wilson, K. J. (1971) J. Biol. Chem.246, 1756-1764.

24 Saxena, V. P., and Wetlaufer, D. B. (1971) Proc. Natl. Acad. Sci. U.S.A.68, 969-972.

25 Arnold, F. H. (1988) Protein Eng.2, 21-25.

26 Gomez-Puyou, M.-T., and Gomez-Puyou, A. (1998) Crit. Rev. Biochem. Mol. Biol.33, 53-89.

27 Kelly, S. M., and Price, N. C. (1997) Biochim. Biophys. Acta1338, 161-185.

28 Cleland, W. W. (1979) Methods Enzymol.63, 103-138.

29 Segel, I. H. (1975) Enzyme Kinetics: Behavior and analysis of rapid equilibrium and steady-state enzyme systems., 1st ed., John Wiley \& Sons, New York.

30 Prescott, J. M., Wagner, F. W., Holmquist, B., and Vallee, B. L. (1985) Biochemistry24, 5350-5356.

31 Bennett, B., and Holz, R. C. (1997) Biochemistry36, 9837-9846.

32 Spungin, A., and Blumberg, S. (1989) Eur. J. Biochem.183, 471-477.

33 Ben-Meir, D., Spungin, A., Ashkenazi, R., and Blumberg, S. (1993) Eur. J. Biochem.212, 107-112.

34 Kim, H., and Lipscomb, W. N. (1993) Biochemistry32, 8465-8478.

35 Taylor, A., Volz, K. W., Lipscomb, W. N., and Takemoto, L. J. (1984) J. Biol. Chem.259, 14757-14761.

36 Allen, M. P., Yamada, A. H., and Carpenter, F. H. (1983) Biochemistry22, 3778-3783.

37 Greenblatt, H. M., Almog, O., Maras, B., Spungin-Bialik, A., Barra, D., Blumberg, S., and Shoham, G. (1997) J. Mol. Biol.265, 620-636.

38 Schmitke, J., Wescott, C. R., and Kilbanov, A. M. (1996) J. Am. Chem. Soc.118, 3360-3365.

39 Griebenow, K., and Klibanov, A. M. (1996) J. Am. Chem. Soc.118, 11695-11700.

40 Oda, K., Okayama, K., Okutomi, K., Shimada, M., Sato, R., and Takahashi, S. (1996) Biosci. Biotech. Biochem.60, 463-467.

41 Prescott, J. M., and Wilkes, S. H. (1966) Arch. Biochem. Biophys.117, 328-336.

42 Bennett, B., and Holz, R. C. (1998) J. Am. Chem. Soc.120, 12139-12140.

43 Baker, J. O., and Prescott, J. M. (1983) Biochemistry22, 5322-5331.

44 Walker, K. W., and Bradshaw, R. A. (1999) J. Biol. Chem.274, 13403-13409.

1 Abbreviations: AAP (aminopeptidase from Aeromonas proteolytica); bILAP (bovine lens leucine aminopeptidase); MetAP (methionyl aminopeptidase from E. coli); AMPP (aminopeptidase-P from $E$. coli); $v$ (velocity); $V_{\max }$ (maximal velocity); $k_{\mathrm{cat}}\left(V_{\max } /[\mathrm{E}]_{\mathrm{o}}\right) ; K_{\mathrm{m}}$ (Michaelis constant); $K_{\mathrm{i}}$ (inhibition constant); [S] (substrate concentration); [I] (inhibitor concentration); Tricine ( $N$-tris(hydroxymethyl)methylglycine). 